\title{
EDUCAÇÃO DE JOVENS E ADULTOS (EJA): A LUTA PELO DESENVOLVIMENTO DA CIDADANIA
}

\author{
SILVA, Giseli Serrano da ${ }^{1}$ \\ MARTINS, Maria Sara Abdalla²
}

\begin{abstract}
RESUMO: A Educação de Jovens e Adultos (EJA) consiste em uma modalidade de ensino que oferece o direito à educação às pessoas que não tiveram acesso ao ensino fundamental e médio na idade própria. Este estudo apresenta os resultados de uma pesquisa bibliográfica que inclui histórico, políticas públicas, diretrizes curriculares, docência e perspectivas discentes e uma pesquisa de campo de natureza qualitativa. A coleta de dados foi realizada através de questionários com questões abertas dirigidas a educadores e educandos e uma produção de textos para alunos de $2^{\mathrm{a}} \mathrm{e}$ $4^{\mathrm{a}}$ séries de uma escola municipal de Ituverava. O objetivo geral deste estudo foi compreender as dinâmicas da EJA no Brasil à luz das políticas públicas educacionais implementadas no país assim como as perspectivas e concepções de professores e alunos. A análise e interpretação dos dados mostraram a importância da alfabetização e do curso para o desenvolvimento de uma aprendizagem consciente que impulsiona a cidadania e o ingresso ao mercado de trabalho.
\end{abstract}

Palavras-chave: Educação de jovens e adultos. Políticas públicas educacionais. Formação docente. Analfabetismo. Cidadania.

SUMMARY: The Youth and Adults Education (EJA) consist of a teaching modality that offers the right to education to people who lacked access to primary and secondary schools as they age. This study presents the results of a bibliographic research that includes historic, public policy, curriculum guidelines, teaching and students' perspectives and field research of qualitative nature. Data collection was conducted using questionnaires with open questions aimed at educators and students and a production of texts for students in 2nd and 4th grade in a school hall of Ituverava. The purpose of this study was to understand the dynamics of AYE in Brazil by the light of public educational policies implemented in the country as well as the perspectives and insights of teachers and students. The analysis and interpretation of data showed the importance of literacy and of course for the development of a conscious learning that fosters citizenship and the entry to the labor market.

Keywords: Youth and adults education. Public policy education.Teacher training. Illiteracy. Citizenship.

\section{INTRODUÇÃO}

O presente trabalho se justifica pela necessidade de conhecimento e compreensão acerca das complexas abrangências da EJA e dos atores do processo. É importante saber quem são os educandos deste segmento de ensino e como na práxis conceituam e significam as suas aprendizagens. E também como os educadores lidam com a diversidade.

É importante trabalhar a alfabetização de adultos como fator de direitos e pela busca da dignidade e cidadania, cuja questão é colocada como ponto de partida para o resgate de dignidade, a defesa ética e a transformação do cidadão analfabeto para alfabetizado, com consciência crítica e política e o porquê de terem perdido o tempo certo de escola e só agora poderem ter a oportunidade de estarem em uma sala de aula.

A Educação de Jovens e Adultos na perspectiva de orientação para o desenvolvimento integral do ser humano vem ganhando força no mundo contemporâneo.

Educar jovens e adultos hoje não é apenas ensiná-los a ler e escrever seu próprio nome. É oferecer-

\footnotetext{
${ }^{1}$ Graduada em Pedagogia na FE/FFCL. E-mail: giseliserrano321@hotmail.com

${ }^{2}$ Mestre em Educação. Prof ${ }^{a}$. Pedagogia na FE/FFCL. E mail: abdallamartins @ netsite.com.br
} 
lhes uma escolarização ampla e com qualidade. O que se pretende atualmente não é apenas reduzir números e índices de analfabetismo e sim se ocupar de fato com a cultura do educando, com sua qualificação para o mercado de trabalho e o seu próprio exercício da cidadania.

Apesar de todas as razões sociais e políticas para não depositar a responsabilidade pelo fracasso escolar no aluno, as teorias da carência cultural e do déficit cognitivo acabaram por consolidar a ideia de que a possibilidade de indivíduos aprenderem teria relação direta com sua condição econômica, social e cultural.

Com isso, consolidou-se progressivamente uma cultura escolar da repetência e do abandono escolar como fenômenos naturais e o país foi se acostumando com o fato de cerca de metade de seus alunos não se alfabetizarem.

Todo aluno tem direito a uma educação escolar que, pautada no princípio da igualdade, garante o conhecimento necessário para que desenvolva suas diferentes capacidades. É preciso uma educação onde não acontece às diferenças provocadas pela desigualdade de oportunidades sociais e culturais e que não as tome, sob nenhum pretexto, como diferenças relacionadas às suas possibilidades de aprendizagem.

Portanto o motivo de se estudar a Educação de Jovens e Adultos, pauta-se na averiguação da luta pela cidadania daqueles alunos que não tiveram oportunidade de estudar, perdendo uma preciosa parte de sua vida e que agora querem recuperar o que deixaram para trás tanto como conhecimento como aprendizagem de conteúdos.

O objetivo do trabalho será compreender as dinâmicas da EJA no Brasil à luz das políticas públicas educacionais implementadas no país assim como as perspectivas e concepções de professores e alunos.

\section{VISÃO TEÓRICA DA EDUCAÇÃO DE JOVENS E ADULTOS NO BRASIL}

A Educação de Jovens e adultos é uma modalidade de ensino amparada por leis e voltada para pessoas que não tiveram acesso, por algum motivo ao ensino regular na idade própria.

De acordo com Haddad; Pierro (2000), a educação de adolescentes e adultos já vem de longa data no Brasil. Sabe-se que no Brasil Colônia os jesuítas trabalhavam suas ações educativas missionárias em boa parte dos adultos, difundindo o evangelho e transmitindo suas regras de comportamento, de primeiro momento, com os índios e, mais tarde, com os escravos negros, isto até meados do século XVIII, quando os religiosos foram expulsos do Brasil. Com a Primeira Constituição, em 1824, foi garantido o direito à instrução primária para todos, porém, quase nada foi realizado no campo da Educação de Jovens e Adultos (EJA) no período Imperial, ficando apenas na intenção. No período Imperial, apenas uma parte das pessoas (a elite) possuíam acesso à educação, sendo que a grande maioria de índios, negros e mulheres eram excluídas.

No início do século XIX, cerca de 70\% da população adulta era analfabeta. Segundo Moll (1996), o país demonstrava total ineficácia no combate ao analfabetismo, pois os órgãos responsáveis pela educação do país não se preocupavam com a questão, como por exemplo, o Ministério da Guerra. Em 1915 organiza-se a Liga Brasileira Contra o Analfabetismo em reunião feita no Clube Militar do Rio de Janeiro. Muitos afirmavam que tal Liga representava a explicitação da "Ideologia da inferioridade intrínseca do Analfabeto".

O lema da Liga era: "Combater o analfabetismo é dever de honra de todo brasileiro" e discursos feitos pela Liga demonstravam tal ideologia como: "expurgar a praga negra"; "maior inimigo do Brasil", "libertar do cativeiro do analfabetismo". Apesar desses movimentos, no final da década haviam aproximadamente $75 \%$ de analfabetos no país. 
A Revolução de 1930 é considerada um marco em relação à educação, com uma grande inclinação ao fortalecimento e a mudança de papel do Estado Central. Nos aspectos educacionais, a nova Constituição, de 1930, propôs um Plano Nacional de Educação regido pelo governo federal, deixando claro, os papeis da União, Estados e Municípios. A nova Constituição Republicana também proibiu voto dos analfabetos, sendo que, em tal momento, a maioria da população adulta era iletrada.

No início da década de 60, o Ministério da Educação organizou o último dos programas de corte nacional desse ciclo, o Programa Nacional de Alfabetização de Adultos, cujo planejamento acabou incorporando as orientações de Paulo Freire, que foi, para todos os mais célebres educadores brasileiro, conhecido principalmente pelo método de alfabetização de adultos que levava o seu nome, ele desenvolveu um pensamento pedagógico assumidamente político.

De acordo com a revista Nova Escola (Coleção: Grandes Pensadores 2006), o maior objetivo de Freire na educação é conscientizar o educando, ou seja, levar a educação às parcelas desfavorecidas pela sociedade, entender sua situação de oprimidas e agir em favor da própria libertação.

Ainda segundo a Revista Nova Escola (Coleção Grandes Pensadores; Paulo Freire: O mentor da educação para a consciência, 2006, p.111) ressalta que:

Freire previa para o professor um papel diretivo e informativo, portanto não pode renunciar sua autoridade, pois o aluno alfabetizado ou não, chega à escola uma cultura que não é melhor nem pior que a do professor. Na sala de aula ambos aprenderão juntos, um com o outro e para isso é necessário que as relações sejam afetivas e democráticas, garantindo a todos a possibilidade de se expressar.

A alfabetização é para o educador, uma forma de os desfavorecidos romperem com o que ele chamou de "a cultura do silêncio" e transformar a realidade, como sujeitos da própria História.

O grande sentido da alfabetização para Freire, segundo Fiori (apud FREIRE, 2006, p.8) é:

Aprender a escrever sua própria vida, como autor e testemunha de sua história, isto é, biografar-se, existenciar-se, historicizar-se. Por isso, a pedagogia de Paulo Freire, sendo método de alfabetização, tem como idéia animadora toda a amplitude humana da "educação como prática da liberdade", o que em regime de dominação, só se pode produzir e desenvolver na dinâmica de uma pedagogia do oprimido.

Em 1962, na cidade de Angicos no Rio Grande do Norte, levou suas ideias pedagógicas denominadas posteriormente de "Método Paulo Freire", que se formaram a partir da observação da cultura dos alunos e do papel elitista da escola. Seu programa alfabetizou 300 pessoas em um mês.

O método Paulo Freire tinha como ponto fundamental as Palavras Geradoras, sendo assim, a Revista Nova Escola (Coleção Grandes Pensadores; Paulo Freire: O mentor da educação para a consciência, 2006, p.111) afirma que o "Método Paulo Freire" passa por três etapas rumo à conscientização. Sua teoria se distingue em três momentos distintos:

O primeiro é aquele que o educador se intera daquilo que o aluno conhece, não apenas para poder avançar no ensino de conteúdos, mas principalmente para trazer a cultura do educando para dentro da sala de aula. O segundo momento é o de exploração das questões relativas aos temas em discussão, o que permite que o aluno construa o caminho do senso comum para a visão crítica e finalmente, volta-se do abstrato para o concreto, na chamada etapa de problematizarão, o conteúdo em questão apresenta-se dissecado, o que deve sugerir ações para superar impasses. Para Freire, esse procedimento serve ao objetivo final do ensino, que é a conscientização do aluno.

Após a prisão e extradição de Freire, em 1969, o governo federal organiza e lança o Mobral (Movimento Brasileiro de Alfabetização), um programa de proporções nacionais com a intenção de oferecer uma alfabetização a uma vasta parcela de adultos analfabetos nas mais variadas regiões do Brasil, investindo o governo significativos recursos na montagem do próprio Mobral. Foram instaladas comissões municipais por todo país com a responsabilidade de execução das atividades, criado com ação que se extinguiria depois de resolvido o problema do analfabetismo no país. 
Desacreditado nos meios políticos e educacionais, o Mobral foi extinto em 1985, quando o processo de abertura política já estava relativamente avançado, os recursos financeiros diminuíram e o que restou de estruturas do Mobral transformou-sena Fundação Educar, que passou a apoiar técnica e financeiramente iniciativas de governos federais, municipais e entidades particulares, abrindo mão do controle político pedagógico que caracterizava até então a ação do Mobral.

No início dos anos 90, foi extinta a Fundação Educar, sucessora do Mobral, logo após a posse do governo Fernando Collor, primeiro presidente eleito pelo voto direto (BEISIEGEL, 1999 apud HADDAD; PIERRO, 2000). A falta de incentivo político e financeiro por parte do governo federal levou os programas estatais responsáveis pela maior parte do atendimento à educação de jovens e adultos a uma situação de estagnação e declínio e muitos municípios herdeiros de programas realizados anteriormente em convênio com a Fundação Educar foram obrigados a assumi-los com seus próprios recursos.

A demanda pelo ensino fundamental de jovens e adultos é extensa e complexa, comportando em seu interior uma grande diversidade de necessidades formativas, considerando hoje a necessidade de consolidar a alfabetização funcional dos indivíduos em questão. Isso não significa que a educação de jovens e adultos devia reproduzir as formas de organização, currículos, métodos e materiais da educação básica infanto-juvenil,ao contrário, é preciso flexibilizar currículos, meios e formas de atendimento, favorecendo processos de aprendizagem formais e informais, para que tais indivíduos possam obter novas aprendizagens (PIERRO ET al., 2001).

Nesse sentido, os governos precisam assumir mais claramente uma atitude inovadora, chamando todos os interessados a engajarem-se mais em iniciativas voltadas pra a elevação do nível educativo da população.

Em janeiro de 2003, o MEC (Ministério da Educação e Cultura) anunciou que a EJA seria prioridade do governo federal e, por isso, foi criada a Secretaria Extraordinária de Erradicação do Analfabetismo, cuja meta era erradicar o analfabetismo em quatro anos. Para alcançar tal meta, foi criado o programa Brasil Alfabetizado, com duas ações a serem feitas: a Alfabetização de Jovens e Adultos e a Formação de Alfabetizadores. Para o alfabetizador, é necessário que ele tenha um conhecimento prévio do grupo que irá trabalhar para que o processo de alfabetização seja "participativo e democrático". O programa continua em andamento até hoje e, por isso, não é possível afirmar se os objetivos do Governo Federal e MEC foram alcançados.

Passando pela história das políticas públicas, o Brasil passa pelo século XIX e XX, com muitas falhas e poucos progressos. Um dos poucos progressos que podemos citar é a promulgação da Constituição de 1988 que estabeleceu alguns pontos positivos relativos à Educação de Jovens e adultos. Em seu artigo 208, ela "legitima o direito a escolarização a todos independente de idade". No Capítulo III, Seção I,Da Educação,no mesmo artigo, a constituição define que:

[...] o dever do estado será efetivado mediante garantia de:

I - ensino fundamental, obrigatório e gratuito, inclusive para os que a ele não tiveram acesso em idade própria;

II - extensão da obrigatoriedade e gratuidade ao ensino médio.

Ainda sobre a Constituição de 1988, ela deixou declarada nas formas da lei o direito de todos à Educação. Outro artigo importante foi definido:

Artigo 214. A lei estabelecerá o plano nacional de Educação, de duração plurianual, visando à articulação e ao desenvolvimento do ensino em diversos níveis e à integração das ações do poder público que conduzam à:

I - erradicação do analfabetismo;

II - universalização do atendimento escolar.

Tais artigos se tornaram fundamentais para o surgimento dos fundos de investimentos para a Educação (FUNDEF e posteriormente o FUNDEB).

Em 20 de dezembro de 1996, foi promulgada a LDB n 9394 que estabelece, em seu art.37 que a educação de jovens e adultos será destinada àqueles que não tiveram acesso ou continuidade de estudos no ensino fundamental e médio na idade própria. Outro ponto importante da LDB é do artigo 38 que afirma:

"Os sistemas de ensino manterão cursos e exames supletivos, que comprenderão a base nacional comum do currículo, habilitando ao prosseguimento de estudos em caráter regular". 
A educação de jovens e adultos é sempre relacionada a projetos de desenvolvimento econômico, e o processo de significação acaba ficando alicerçado na ideologia compensatória com ênfase na educação. Tal modalidade de educação é, portanto, compensatória, supletiva e tem função adaptativa, está presente na atual LDB, assim como já estava presente na Lei n. 5692/71 da época da ditadura militar.

\section{DIRETRIZES CURRICULARES NACIONAIS PARA EDUCAÇÃO DE JOVENS E ADULTOS E UM CURÍCULO MAIS ADEQUADO NA EJA}

De acordo com a análise de Gonçalves (2000), diversas iniciativas governamentais vêm tratando a educação de jovens e adultos sempre na perspectiva das campanhas de analfabetismo e, às vezes, na ótica do voluntariado e paralela ao sistema educacional. Tais atitudes, mais a incapacidade da escola pública, em possibilitar o acesso ao conhecimento à população por ela atendida, teve como resultado o abandono dos estudos por um enorme contingente jovem, sem concluir a escola regular, levando grande número de jovens a ser excluídos da escola. E é sobre tal circunstância que entra a EJA, uma população de jovens e adultos não analfabetos, mas que interromperam o processo escolar, sendo que, tal campo educacional tem se constituído como um campo de práticas e de reflexão sobre o desenvolvimento integral dos sujeitos sociais matriculados nessa modalidade de ensino.

Haddad (2000) afirma que após o levantamento das pesquisas na EJA, se constatou a ausência de estudos sobre um currículo voltado pra esse tipo de ensino e em relação aos destinatários dos cursos e programas e a preocupação com o seu público-alvo. O currículo não é um campo neutro de conhecimentos, precisa ser visto e estudado como um campo onde estruturas econômicas e sociais estão em luta para se adequarem as reais necessidades dos alunos.

A EJA apresenta um currículo maleável e flexível, adequando-se a que se destina. Considerando sua importância específica, o desenvolvimento do trabalho pedagógico a partir das histórias de vida, dos interesses e dos saberes que os alunos trazem para a sala de aula, a reflexão sobre a questão dos conteúdos a serem trabalhados assume uma dimensão que lhe é específica.

De acordo com as recomendações internacionais da CONFEA VI (2009) (Conferência Internacional de Jovens e Adultos) o currículo deve ter como principais metas:

A alfabetização é para o educador, uma rorma de os desfavorecidos romperem com o que ele chamou de "a cultura do silêncio" e transformar a realidade, como sujeitos da própria História.

O grande sentido da alfabetização para Freire, segundo Fiori (apud FREIRE, 2006, p.8) é:

Em 1962, na cidade de Angicos no Rio Grande do Norte, levou suas ideias pedagógicas denominadas posteriormente de "Método Paulo Freire", que se formaram a partir da observação da cultura dos alunos e do papel elitista da escola. Seu programa alfabetizou 300 pessoas em um mês.

O método Paulo Freire tinha como ponto fundamental as Palavras Geradoras, sendo assim, a Revista Nova Escola (Coleção Grandes Pensadores; Paulo Freire: O mentor da educação para a consciência, 2006, p.111) afirma que o "Método Paulo Freire" passa por três etapas rumo à conscientização. Sua teoria se distingue em três momentos distintos:

Após a prisão e extradição de Freire, em 1969, o governo federal organiza e lança o Mobral (Movimento Brasileiro de Alfabetização), um programa de proporções nacionais com a intenção de oferecer uma alfabetização a uma vasta parcela de adultos analfabetos nas mais variadas regiões do Brasil, investindo o governo significativos recursos na montagem do próprio Mobral. Foram instaladas comissões municipais por todo país com a responsabilidade de execução das atividades, criado com ação que se extinguiria depois de resolvido o problema do analfabetismo no país.

Desacreditado nos meios políticos e educacionais, o Mobral foi extinto em 1985, quando o processo de abertura política já estava relativamente avançado, os recursos financeiros diminuíram e o que restou de estruturas do Mobral transformou-sena Fundação Educar, que passou a apoiar técnica e financeiramente iniciativas de governos federais, municipais e entidades particulares, abrindo mão do controle político pedagógico que caracterizava até então a ação do Mobral.

No início dos anos 90, foi extinta a Fundação Educar, sucessora do Mobral, logo após a posse do governo Fernando Collor, primeiro presidente eleito pelo voto direto (BEISIEGEL, 1999 apud HADDAD; PIERRO, 2000). A falta de incentivo político e financeiro por parte do governo federal levou os programas estatais responsáveis pela maior parte do atendimento à educação de jovens e adultos a uma situação de estagnação e declínio e muitos municípios herdeiros de programas realizados anteriormente em convênio com a Fundação Educar foram obrigados a assumi-los com seus próprios recursos. 
A demanda pelo ensino fundamental de jovens e adultos é extensa e complexa, comportando em seu interior uma grande diversidade de necessidades formativas, considerando hoje a necessidade de consolidar a alfabetização funcional dos indivíduos em questão. Isso não significa que a educação de jovens e adultos devia reproduzir as formas de organização, currículos, métodos e materiais da educação básica infanto-juvenil,ao contrário, é preciso flexibilizar currículos, meios e formas de atendimento, favorecendo processos de aprendizagem formais e informais, para que tais indivíduos possam obter novas aprendizagens (PIERRO ET al., 2001).

Nesse sentido, os governos precisam assumir mais claramente uma atitude inovadora, chamando todos os interessados a engajarem-se mais em iniciativas voltadas pra a elevação do nível educativo da população.

Em janeiro de 2003, o MEC (Ministério da Educação e Cultura) anunciou que a EJA seria prioridade do governo federal e, por isso, foi criada a Secretaria Extraordinária de Erradicação do Analfabetismo, cuja meta era erradicar o analfabetismo em quatro anos. Para alcançar tal meta, foi criado o programa Brasil Alfabetizado, com duas ações a serem feitas: a Alfabetização de Jovens e Adultos e a Formação de Alfabetizadores. Para o alfabetizador, é necessário que ele tenha um conhecimento prévio do grupo que irá trabalhar para que o processo de alfabetização seja "participativo e democrático". O programa continua em andamento até hoje e, por isso, não é possível afirmar se os objetivos do Governo Federal e MEC foram alcançados.

Passando pela história das políticas públicas, o Brasil passa pelo século XIX e XX, com muitas falhas e poucos progressos. Um dos poucos progressos que podemos citar é a promulgação da Constituição de 1988 que estabeleceu alguns pontos positivos relativos à Educação de Jovens e adultos. Em seu artigo 208, ela "legitima o direito a escolarização a todos independente de idade". No Capítulo III, Seção I,Da Educação,no mesmo artigo, a constituição define que:

Ainda sobre a Constituição de 1988, ela deixou declarada nas formas da lei o direito de todos à Educação. Outro artigo importante foi definido:

Tais artigos se tornaram fundamentais para o surgimento dos fundos de investimentos para a Educação (FUNDEF e posteriormente o FUNDEB).

Em 20 de dezembro de 1996, foi promulgada a LDB n ${ }^{\circ} 9394$ que estabelece, em seu art.37 que a educação de jovens e adultos será destinada àqueles que não tiveram acesso ou continuidade de estudos no ensino fundamental e médio na idade própria. Outro ponto importante da LDB é do artigo 38 que afirma:

A educação de jovens e adultos é sempre relacionada a projetos de desenvolvimento econômico, e o processo de significação acaba ficando alicerçado na ideologia compensatória com ênfase na educação. Tal modalidade de educação é, portanto, compensatória, supletiva e tem função adaptativa, está presente na atual LDB, assim como já estava presente na Lei n. 5692/71 da época da ditadura militar.

De acordo com a análise de Gonçalves (2000), diversas iniciativas governamentais vêm tratando a educação de jovens e adultos sempre na perspectiva das campanhas de analfabetismo e, às vezes, na ótica do voluntariado e paralela ao sistema educacional. Tais atitudes, mais a incapacidade da escola pública, em possibilitar o acesso ao conhecimento à população por ela atendida, teve como resultado o abandono dos estudos por um enorme contingente jovem, sem concluir a escola regular, levando grande número de jovens a ser excluídos da escola. E é sobre tal circunstância que entra a EJA, uma população de jovens e adultos não analfabetos, mas que interromperam o processo escolar, sendo que, tal campo educacional tem se constituído como um campo de práticas e de reflexão sobre o desenvolvimento integral dos sujeitos sociais matriculados nessa modalidade de ensino.

Haddad (2000) afirma que após o levantamento das pesquisas na EJA, se constatou a ausência de estudos sobre um currículo voltado pra esse tipo de ensino e em relação aos destinatários dos cursos e programas e a preocupação com o seu público-alvo. O currículo não é um campo neutro de conhecimentos, precisa ser visto e estudado como um campo onde estruturas econômicas e sociais estão em luta para se adequarem as reais necessidades dos alunos.

A EJA apresenta um currículo maleável e flexível, adequando-se a que se destina. Considerando sua importância específica, o desenvolvimento do trabalho pedagógico a partir das histórias de vida, dos interesses e dos saberes que os alunos trazem para a sala de aula, a reflexão sobre a questão dos conteúdos a serem trabalhados assume uma dimensão que lhe é específica.

De acordo com as recomendações internacionais da CONFEA VI (2009) (Conferência Internacional de Jovens e Adultos) o currículo deve ter como principais metas:

$$
\begin{array}{ll}
\text { - } & \text { Sua inserção } \\
\text { - } & \text { sujeitos de ação; }
\end{array}
$$


- Um currículo v

- Sua inserção num modelo inovador de qualidade para a formação de cidadãos democráticos e sujeitos de ação;

- Um currículo variado que respeite a diversidade de etnias, manifestações regionais e da cultura popular e cujo conhecimento seja fundamentado e, uma construção social fundamentada na interação entre a teoria e a prática;

- $\quad$ Abordar conteúdos básicos, disponibilizando os bens sócios culturais acumulados pela humanidade;
$-$
Colocar as novas tecnologias a disposição da melhoria da atuação dos
- $\quad$ educadores;
- $\quad$ O respeito aos conhecimentos construídos pelos educandos em sua vida cotidiana.

A avaliação também é um importante veículo na prática da Educação de Jovens e Adultos por ser significativa para ambos, pois o educando aprende com ela, e o educador trabalha com a expectativa de que os resultados serão positivos.

Stieh (2010) concorda com Jussara Hoffman que conceitua a avaliação como tomada de consciência da prática avaliativa. Para a autora, a importância da avaliação para o aluno é conhecer os resultados de seus esforços e desempenho, não só pela satisfação de ter aprendido, mas especialmente pelo significado que tem o conhecimento de suas futuras aprendizagens, pois o desafio de resolver sozinho o que não consegue é o que faz o aluno buscar soluções, pois é a partir dos resultados vindos da avaliação que se tem a possibilidade de melhorar sua compreensão das formas de aprendizagem do aluno assim como o processo de ensino aprendizagem.

A autonomia do aluno é essencial até mesmo nas avaliações, mas só com práticas pedagógicas se é possível alcançá-la, pois como diz Freire (1993), com novas práticas que possibilitem a autonomia do indivíduo, integrar-se desenvolvendo a curiosidade e por sua vez chegar ao conhecimento. A observação e o registro também é um modo de trabalhar a avaliação na EJA, pois também é uma forma de aprendizado.

A qualidade do ensino depende muito da relação professor/aluno. O papel da professora EJA é muito importante para o sucesso da aprendizagem do aluno que vê seu professor um modelo a ser seguido.

Falar de jovens e adultos, pessoas que carregam experiências que o tempo lhe permite viver, é considerar os saberes que já trazem consigo, construídos ao longo de suas vidas e, para tal a EJA vem aliar alfabetização às histórias de vida dessas pessoas, construindo para a continuidade de sua formação e evidentemente nesta trajetória todo o professor é um elemento muito importante.

Segundo Pinto (2000, p.113) compete ao professor além de ampliar seus conhecimentos e atualizar-se, o dever de praticar os métodos mais adequados em seu ensino, proceder a uma análise de sua própria realidade como educador, examinar com autoconsciência crítica sua conduta e seu desempenho, com a intenção de ver se está cumprindo aquilo que sua consciência crítica da realidade nacional lhe assinala como sua correta atividade.

Segundo o Parecer CNE/CEB n 4, de 1998: "Nada mais significativo e importante para a construção da cidadania do que a compreensão de que a cultura não existiria sem a socialização das conquistas humanas. O sujeito anônimo é, na verdade, o grande artesão dos tecidos da história". Para que os sujeitos da Educação de Jovens e Adultos se tornem autores de sua própria história é fundamental que deixem a escuridão do analfabetismo para que atinjam a luz do mundo letrado, reconhecendo em si mesmo um novo cidadão, aquele que deixou de ser invisível aos olhos da sociedade para se tornar visível aos olhos de uma sociedade que em muitas vezes só enxergam o que lhe convêm.

Muito foi feito, mas ainda há um longo caminho a ser percorrido, tanto pelos estudantes quanto pelos governantes e profissionais que lidam diretamente com a questão. Políticas educacionais que sejam mais consistentes e eficazes, assim como cursos que trabalhem diretamente com a questão do analfabetismo, exclusão e evasão escolar que são temas diretamente ligados a EJA. A Educação de Jovens e Adultos é mais do que um direito,é a base transformadora de nossa sociedade. 


\section{PERCURSO METODOLOGICO}

Os procedimentos metodológicos que permitiram a realização deste trabalho partem de uma abordagem qualitativa. Ele foi realizado por meio de uma pesquisa bibliográfica dirigida ao tema Educação de Jovens e Adultos e em conjunto com uma pesquisa de campo para verificar vários dados relevantes à temática e voltadas para a realidade daqueles que procuram a EJA, assim como para os educadores que trabalham nesta modalidade de ensino.

Na pesquisa bibliográfica utilizaram-se obras de vários autores como Paulo Freire, Sergio Haddad, Maria Clara Di Pierro, Jaqueline Moll, Magda Soares, Fiori (apud Freire) e vários artigos publicados em sites específicos para a educação, assim como a revista destinada aos educadores Nova Escola.

$\mathrm{Na}$ pesquisa de campo foi aplicado um questionário com questões abertas, específico para educadores e educandos. Outra atividade aplicada foi a produção de texto feita pelos alunos das $2^{\mathrm{a}}$ e $4^{\mathrm{a}}$ séries, intitulada de "Cartas ao leitor," que teve como objetivo descobrir os anseios e perspectivas que os mesmos têm para o futuro.

Para a análise e interpretação dos dados assim como as considerações finais foram usados os resultados obtidos nos questionários e nas produções de texto, nos trechos de diálogos e observações realizadas durante a pesquisa de campo assim como comportamentos, a análise das escritas e dos conteúdos.

\section{COLETA, ANALISE E INTERPRETAÇÃO DOS DADOS}

Esta pesquisa foi desenvolvida em uma escola pública municipal de Ituverava. Os dados foram colhidos de junho a setembro de 2010. Para sua realização foi escolhido à coleta de dados (questionário para educador e educandos) e a produção de texto em que os alunos da $4^{\mathrm{a}}$ série deveriam escrever uma carta para alguém e os da $2^{a}$ série deveriam escrever um bilhete. Sendo assim, essa pesquisa teve caráter qualitativo, especificando - se na pesquisa de campo.

A análise do questionário das duas educadoras cujas idades variam entre 30 a 40 anos, indicou coerência entre as respostas como na quarta questão onde foi perguntado sobre os recursos que utilizam em sala de aula e ambas responderam que trabalham com os mais variados recursos. Outra questão muito interessante foi sobre o crédito que dão para a Educação de Jovens e Adultos, ambos responderam que tal modalidade de ensino significa "transformação da sociedade". A postura das educadoras diante do trabalho exercido demonstra total desempenho, afetividade, capacidade e respeito para com a profissão e para com o educando,estando de acordo com a afirmação da Revista Nova Escola (Coleção Grandes Pensadores; Paulo Freire: O mentor da educação para a consciência, 2006, p.111) feita no primeiro capítulo sobre a visão de Freire do papel do professor que deve ser "diretivo e informativo pois na sala de aula ambos aprenderão juntos", devendo assim respeitar a cultura e expressão do aluno e para isso é necesario contruir uma relação democrática e afetiva .

Cerca de três semanas depois foi aplicado o questionário com os alunos das duas salas, ou seja, das $4^{\mathrm{a}}$ e $2^{\mathrm{a}}$ série. $\mathrm{Na} 2^{\circ}$ série dos 18 alunos apenas cinco alunos participaram da aplicação do questionário e só responderam oralmente, negando-se a escrever. Já na $4^{\circ}$ série, dos 21 alunos, nove alunos se dispuseram a responder o questionário sozinhos para mostrarem suas competências e habilidades.

Foi aplicado o questionário, primeiro com os alunos do $4^{\circ}$ série, depois com os da $2^{\circ}$. As questões foram às mesmas para ambas as turmas, sendo no total de oito questões. Veremos a seguir, um resumo das respostas mais interessantes e significativas dos educandos.

$\mathrm{Na}$ turma da $4^{\circ}$ série as idades dos alunos variam entre 18 e 53 anos. As respostas foram diferentes para as diversas questões, o que mostra as individualidades e interesses de cada um, seus conhecimentos prévios e suas expectativas para o futuro. Foi possível observar que os alunos realizaram o trabalho proposto de acordo com os conhecimentos adquiridos em sala de aula e as habilidades que já possuem como foi citado por Freire (2006) no primeiro capítulo sobre a importância de se valorizar os conhecimentos prévios do aluno, ou seja, o uso das palavras geradoras trabalhadas em sala de aula, pois todo o contexto das aulas é norteado pela vivência do aluno, isto é, suas experiências de vida.

$\mathrm{Na} 2^{\mathrm{a}}$ série as respostas dos alunos demonstraram algumas opiniões parecidas com as da $4^{\circ}$ série como "melhorar de emprego, melhorar de vida" e a grande importância que deram ao fato de "aprender a ler e escrever" e como podem lutar por seus ideais agora que estão alfabetizados, mostrando mais uma vez a coesão das respostas com a visão de Freire sobre o verdadeiro sentido da alfabetização, que segundo Fiori (apud Freire2006, p. 8) é "aprender a escrever a própria vida,como autor e testemunha de sua própria história".

Uma semana depois do término da aplicação dos questionários foi aplicada a segunda parte da

Nucleus, v.9, n.1, abr.2012 
pesquisa de campo, a produção de texto que foi intitulada de "Cartas ao Leitor". Seguindo a mesma linha dos questionários foi aplicada a produção de texto primeiramente para a turma da $4^{\circ}$ série. Na semana seguinte foram feitas as produções de texto da $2^{\circ}$ série.

A produção de texto comentada aqui é do aluno da $4^{\mathrm{a}}$ série com a idade de 34 anos. Sua escrita é alfabética, sendo que é possível observar que sua carta quase não tem erros ortográficos e uma letra cursiva impecável. Ele explicou em poucas palavras o real valor da escola em sua vida. No trecho final ele resume em poucas palavras o significado do termo recomeço: "E agora que estou recomeçando e estou vendo o quanto é bom estudar já posso sonhar com um futuro melhor para mim e minha família".

A segunda produção de texto analisada neste artigo é da aluna da $2^{\mathrm{a}}$ série de 53 anos de idade. Sua escrita é alfabética e assim como as outras alunas se mostrou muito realizada de estar ali naquele momento escrevendo um bilhete para relatar suas experiências na escola. Foi emocionante sua produção, pois demonstrou uma grande sensibilidade e doçura e que apesar de estar com 53 anos pensa em cursar uma faculdade: “... estou muito feliz por que estou estudando e a minha vida melhorou muito depois que comecei a frequentar a sala de aula e pretendo fazer um curso de psicologia".

As análises das produções das $4^{\mathrm{a}} \mathrm{e} 2^{\mathrm{a}}$ séries mostram o quanto é importante não deixar de sonhar e que a idade é apenas um complemento em nossas vidas e não um obstáculo, dando ênfase ao relato de Soares (2006, P.46) sobre o valor da alfabetização consciente e efetiva, ou seja, sobre a importância da pessoa estar alfabetizada e letrada:

\begin{abstract}
À medida que o analfabetismo vai sendo superado [...], a sociedade vai se tornando cada vez mais centrada na escrita, um novo fenômeno se evidencia: não basta apenas aprender a ler e escrever,as pessoas se alfabetizam,aprende a ler e escrever, mas não necessariamente incorporam a prática da leitura e escrita, não necessariamente adquirem competência para usá-las, para envolver-se com as práticas sociais da escrita: não leem livros, jornais [...]. Esse novo fenômeno só ganha visibilidade depois que é minimamente resolvido o problema do analfabetismo e que o desenvolvimento social, cultural, econômico e político traz novas, intensas e variadas práticas de leitura e escrita, fazendo emergirem novas necessidades além de novas alternativas de lazer.
\end{abstract}

A escrita das cartas e dos bilhetes feita pelos alunos confirma a afirmação de Soares (2006), onde o letramento deve estar sempre aliado à prática da leitura e escrita.

Todos os alunos que escreveram as cartas e os bilhetes demonstraram grande alegria e emoção por terem aprendido a ler e escrever. Agora eles não querem mais parar, seguir em frente com os estudos é para eles "um dever" e as produções de textos nos mostram que mesmo após 20, 30 ou 40 anos sem pegar em um lápis, a pessoa tem total capacidade de aprender. Quer ir além, conseguir um emprego melhor, tirar a carta de habilitação ou simplesmente fazer as compras do supermercado sozinhas. E esta é a real importância da Educação de Jovens e Adultos: tirá- lo da escuridão para se tornarem cidadãos realizados.

\title{
CONSIDERAÇÕES FINAIS
}

O trabalho realizado na Educação de Jovens e adultos foi feito com o objetivo de analisar as práticas educativas e pedagógicas da EJA, buscando compreender suas especificidades.

Muitos jovens e adultos sentem necessidade de voltar ou começar a freqüentar a escola, querem aprender a ler e escrever, enriquecer seus conhecimentos. Na sociedade atual a Educação de Jovens e Adultos é uma temática de extrema relevância, uma vez que todos têm o direito de desfrutar dessa prerrogativa, assim como da alfabetização e do letramento e de estudos mais aprofundados visto que estes são necessários para que o cidadão demonstre uma participação ativa nas práticas sociais e vivências com as múltiplas linguagens, inclusive com as novas tecnologias.

Esta modalidade educacional precisa de políticas públicas comprometidas com a formação humanizadora do cidadão e não apenas com a preparação de mão de obra que atenda as demandas do mercado de trabalho. Para que isso ocorra é necessário alfabetizar politicamente a maioria dos cidadãos brasileiros, para que tenha consciência de seus deveres e que saiba reivindicá-los.

Na EJA encontramos pessoas que possuem trajetórias de vida bastante parecidas, fortemente marcadas pela exclusão social e pelo insucesso escolar. Para que ela seja uma alternativa concreta de democratização educacional no Brasil, é necessário contar com políticas publicas pertinentes, consistentes e duradouras, contar com educadores especializados para este segmento de ensino e que saibam usar metodologias e conteúdos diferenciados para um trabalho diversificado. Só assim teremos jovens e adultos motivados para retomarem e contemplarem a educação que deixaram de obter na idade própria. 


\section{REFERÊNCIAS}

BEISIEGEL, C. R. Questões da atualidade na educação popular: ensino fundamental de jovens e adultos ou pouco escolarizados. São Paulo: FEUSP. 1999. In: Haddad, S; Di Pierro, M, C. Escolarização de jovens e adultos. Janeiro de 2000.p 108-130. Disponível

CONFEA VI. Conferência Internacional de Educação Jovem e Adulta. Belém. 2009. 156p .

Disponível

em: $<$ http://www.unesco.org/pt/confinteavi/singleview/news/grale now available online/back/5446/cHas h/f603d1607b/Acesso em: 12 de janeiro de 2010.

COSNTITUIÇÃO: República Federativa do Brasil: Brasília. S. ed. 1988.p.138,141.

FIORI, H. M. Aprender a dizer sua palavra. p.7 -12. In: Freire, P. Pedagogia do oprimido. 39. Ed. Rio de Janeiro: Paz e Terra, 2004.184 p.

FREIRE, P. Professora sim, tia não: cartas a quem ousa ensinar. São Paulo: Olho D'água, 1993.127p .

GONÇALVES, L. A. Negros e educação no Brasil. In: LOPES, E. M. et al. 500 anos de Educação no Brasil. Belo Horizonte: Autêntica. 2000,141p.

HADDAD, S; Di PIERRO, M, C. Escolarização de jovens e adultos. Janeiro de 2000. P108130.Disponível em

$:<$ http://www.anped.org.br/rbe/rbedigital/RBDE14/RBDE14_08_SERGIO_HADDAD_E_MARIA_CLA

RA_DI_PIERRO.pdf Acesso em :15 de dezembro de 2009.

MOLL, J. Alfabetização possível: reinventando o ensinar e o aprender: Porto Alegre: Mediação, 1996. $195 \mathrm{p}$.

PARECER CNE Nº/98 CEB- Aprovado em $1^{\circ}$ de junho de 1998. Assunto: Diretrizes Curriculares Nacionais para o Ensino Médio. Interessado: Conselho Nacional de Educação/Câmara de Educação Básica. Relatora: Conselheira Guiomar Namo de Mello. Processo CNE N 23001.000309/97-46.Relatório de:Fevereiro de 2010.36 P.Disponível em

<http://portalsme.prefeitura.sp.gov.br/Documentos/BibliPed/TextosLegais/LegislacaoEducacional/Parecer CNB_CEB_15_98_InstituiDiretrizesCurricularesNacionaisEnsinoMedio.pdf Acesso em: 29 de dezembro de 2009.

PARECER CNE Nº/98 -CEB - Aprovado em 29 de janeiro de 1998. Assunto: Diretrizes Curriculares para o Ensino Fundamental. Interessada: Câmara de Educação Básica/CNE. Relatora: Conselheira Regina Alcântara de Assis. Processo CNE Nº: 23001.000062/98-76. Janeiro de 1998.32 P. Disponível em: $<$ http://www.crmariocovas.sp.gov.br/pdf/diretrizes_p0387-0401_c.pdf Acesso em: 29 de dezembro de 2009.

PINTO, A. V. Sete lições sobre educação de adultos. 11. Ed. São Paulo: Cortez. 2000.p113.

PIERRO, M, C; JÓIA, O: M, Visões da Educação de Jovens e adultos no Brasil. Novembro de 2001.6 P. Disponível em: $<$ http://www.scielo.br/pdf/ccedes/v21n55/5541.pdf Acesso em: 13 de janeiro de 2010.

MOLL, J. Alfabetização possível: reinventando o ensinar e o aprender: Porto Alegre: Mediação, 1996. $195 \mathrm{p}$.

REVISTA: nova Escola: Coleção Grandes Pensadores. Edição especial. São Paulo, abril, 2006.130p.

SOARES, M. Letramento, um tema em três gêneros. Belo Horizonte: Autêntica, 2006.125p.

STIEH, da G. D. Avaliação da Aprendizagem na eja em ambiente não presencial, Brasília, D. F.

Dezembro de 2005.8 P. Disponível

em: $<$ http://interacaoeducativa.webnode.com.br/news/avalia\%c3\%a7\%c3\%a3o\%20da\%20aprendizagem \% 20na\%20eja\%20em\%20ambiente\%20n\%c3\%a3o\%20presencial/ Acesso em: 08 Jan. 2010.

Nucleus, v.9, n.1, abr.2012 